\title{
Radiological pituitary fossa changes in chronic bronchitis
}

\author{
PD SEMPLE, P MACPHERSON
}

From the Chest Unit, Inverclyde Royal Hospital, Greenock, and Department of Neuroradiology, Southern General Hospital, Glasgow

ABSTRACT Fourteen male patients with chronic bronchitis and hypoxia had a lateral radiograph of the pituitary fossa. Nine of the 14 had definite or probable abnormalities, a significantly higher frequency $(p \leqslant 0.01)$ than is represented by the two out of 14 age-matched men from a control group with head injuries. The most common change was thinning or erosion of the lamina dura. Patients with hypercapnia were no more prone to such abnormalities than were those with normocapnia, a finding that conflicts with a previous paper. We confirm that radiological pituitary fossa changes do occur in chronic bronchitis, that they are unrelated to steroid treatment, and that they are probably not solely due to the chronically raised intracranial pressure associated with hypercapnia. Other possible mechanisms are discussed-in particular hypoxia, which might produce changes on account of the increased cerebral blood flow and engorged intracranial blood vessels.

Newton and colleagues ${ }^{1}$ described seven patients with chronic bronchitis and associated chronic hypercapnia and one with intermittent hypercapnia, all of whom had radiological pituitary fossa abnormalities. Such changes had not previously been described and they ascribed them to raised intracranial pressure caused by hypercapnia as they found no such radiological changes among control bronchitic patients with normal carbon dioxide tensions. They made no mention of blood oxygen levels in patients or controls.

Recently one of us (PDS) with coworkers has demonstrated some previously unrecognised and far-reaching metabolic and hormonal effects of chronic hypoxia in such patients..$^{2-4}$ Accordingly we have now repeated the above study using demonstrably hypoxic chronic bronchitic patients, some with and some without hypercapnia, to determine whether or not such radiological changes are indeed related exclusively to the raised intracranial pressure of hypercapnia.

\section{Methods}

Approval for the project was granted by the hospital ethical committee and informed written consent was obtained from all patients. Fourteen male patients

Address for reprint requests: Dr PD Semple, Inverclyde Royal Hospital, Larkfield Road, Greenock PA16 0XN. of the chest clinic, age range 32-62 years, were chosen to represent a wide range of arterial blood gas tensions. All were considered to have chronic bronchitis, in view of cough and sputum production on most days of the year for over three years, and had grade 3 or 4 dyspnoea $^{5}$; their condition was stable. None was having steroid treatment. By spirometry (Vitalograph, sitting) the forced expiratory volume in one second $\left(\mathrm{FEV}_{1}\right)$ was always less than $70 \%$ of the predicted normal value ${ }^{6}$ and forced expiratory volume:forced vital capacity ratio $\left(\mathrm{FEV}_{1} / \mathrm{FVC} \%\right)$ was invariably less than $70 \%$, signifying airways obstruction. Arterial blood gases were measured on two occasions at least two months apart, each sample for blood gas estimation being taken from the radial artery after the patient had breathed room air at rest for 15 minutes. The severity of dyspnoea, pulmonary function results, and arterial blood gas tensions are illustrated in the table.

Each patient had a coned lateral radiograph of the pituitary fossa made with a high-definition technique. ${ }^{7}$ Fourteen age-matched men who attended with head injuries had a similar coned radiograph taken in addition to the routine skull radiograph and acted as a control group. The films were read by a neuroradiologist (PM) who was not aware of the individual clinical state or blood gas measurements. The abnormalities were categorised as follows: $\mathbf{A}=$ thinning of the lamina dura; $B=$ erosion of the lamina dura of the dorsum sellae; $\mathrm{C}=$ erosion of the 
Summary of results of pulmonary function tests, arterial blood gas tensions, pituitary fossa $\mathrm{x}$-ray appearances, and smoking habit in male patients with chronic bronchitis

\begin{tabular}{|c|c|c|c|c|c|c|c|c|}
\hline $\begin{array}{l}\text { Case } \\
\text { No }\end{array}$ & Age & $\begin{array}{l}F E V_{1} \\
(l)\end{array}$ & $\begin{array}{l}F E V_{1} / F V C \\
(\%)\end{array}$ & $\begin{array}{l}\text { Grade of } \\
\text { dyspnoea }\end{array}$ & $\begin{array}{l}\text { Mean } \\
\mathrm{PaO}_{2} \\
(\mathrm{kPa})\end{array}$ & $\begin{array}{l}\text { Mean } \\
\mathrm{PaCO}_{2} \\
(\mathrm{kPa})^{2}\end{array}$ & $\begin{array}{l}\text { Pituitary } \\
\text { fossa x-ray } \\
\text { appearance }\end{array}$ & $\begin{array}{l}\text { Smoking } \\
\text { (cigarettes/day) }\end{array}$ \\
\hline $\begin{array}{r}1 \\
2 \\
3 \\
4 \\
5 \\
6 \\
7 \\
8 \\
9 \\
10 \\
11 \\
12 \\
13 \\
14\end{array}$ & $\begin{array}{l}43 \\
53 \\
51 \\
50 \\
36 \\
57 \\
53 \\
52 \\
60 \\
62 \\
49 \\
54 \\
49 \\
57\end{array}$ & $\begin{array}{l}0.75 \\
0.85 \\
0.5 \\
0.9 \\
0.8 \\
0.8 \\
0.75 \\
1.7 \\
0.9 \\
2.25 \\
2.0 \\
1.8 \\
2.0 \\
0.65\end{array}$ & $\begin{array}{l}27 \\
34 \\
50 \\
60 \\
57 \\
66 \\
37 \\
59 \\
47 \\
64 \\
57 \\
58 \\
52 \\
65\end{array}$ & $\begin{array}{l}4 \\
4 \\
4 \\
4 \\
4 \\
4 \\
4 \\
3 \\
4 \\
4 \\
4 \\
4 \\
3 \\
4\end{array}$ & $\begin{array}{l}5 \cdot 6 \\
4 \cdot 4 \\
5 \cdot 5 \\
5 \cdot 3 \\
6 \cdot 3 \\
5 \cdot 6 \\
7 \cdot 2 \\
7 \cdot 9 \\
7 \cdot 1 \\
9 \cdot 3 \\
9 \cdot 9 \\
7 \cdot 5 \\
9 \cdot 6 \\
9 \cdot 2\end{array}$ & $\begin{array}{l}8 \cdot 1 \\
7 \cdot 3 \\
8 \cdot 9 \\
7 \cdot 3 \\
7 \cdot 7 \\
7 \cdot 6 \\
7 \cdot 7 \\
6 \cdot 6 \\
5 \cdot 2 \\
4 \cdot 7 \\
4 \cdot 7 \\
5 \cdot 7 \\
5 \cdot 3 \\
4 \cdot 5\end{array}$ & $\begin{array}{l}\text { Normal } \\
{ }^{*} \mathrm{~B}, \mathrm{C} \\
\text { Normal } \\
{ }^{*} \mathrm{~B} \\
+\mathrm{A} \\
+ \text { Normal } \\
\text { Normal } \\
\text { Normal } \\
+\mathrm{A}, \mathrm{C} \\
+\mathrm{B} \\
{ }^{*} \mathrm{~B}, \mathrm{D} \\
\dagger \mathrm{A} \\
{ }^{*} \mathrm{~B} \\
{ }^{*} \mathrm{~B}\end{array}$ & $\begin{array}{l}20 \\
15 \\
\text { Ex-smoker } \\
20 \\
60 \\
\text { Non-smoker } \\
40 \\
30 \\
40 \\
50 \\
40 \\
30 \\
20 \\
40\end{array}$ \\
\hline
\end{tabular}

$\mathrm{FEV}_{1}=$ one-second forced expiratory volume; $\mathrm{FVC}=$ forced vital capacity; $\mathrm{PaO}_{2}=$ arterial oxygen tension; $\mathrm{Paco}_{2}=$ arterial carbon dioxide tension. $\mathrm{A}=$ thinning of the lamina dura; $\mathrm{B}=$ erosion of the lamina dura of the dorsum sellae; $\mathrm{C}=$ erosion of the floor of the pituitary fossa; $D=$ general reduced density of the dorsum sellae.

* = definitely abnormal; $\dagger=$ probably abnormal; $\ddagger=$ probably normal.

Conversion: SI to conventional units-Blood gases: $1 \mathrm{kPa}=7.5 \mathrm{~mm} \mathrm{Hg}$.

floor of the pituitary fossa; $\mathrm{D}=$ general reduced density of the dorsum sellae. This method is identical to that used by Newton and colleagues except for the addition of category $\mathrm{D}$. The films were jumbled and reassessed at a second sitting and scores compared with those assigned at the first sitting. Films scored as normal or abnormal on both occasions were so classified. Where the two scores conflicted these doubtful films were again jumbled and rescored on two separate occasions. Where they had become 3:1 normal:doubtful they were called "probably normal" and where they were $2: 2$ or $1: 3$ normal:abnormal/doubtful they were called "probably abnormal." Statistical comparisons were made with the $\chi^{2}$ test.

\section{Results}

Of the 14 patients, six had abnormal and three had probably abnormal pituitary fossa films, whereas in the control group one patient had an abnormal and one a probably abnormal film. This is a significant difference $(p<0.01)$. When the group of patients was divided into those with normocapnia (carbon dioxide tension $\leqslant 5.9 \mathrm{kPa}(44 \mathrm{~mm} \mathrm{Hg})$ and those with hypercapnia $\left(\mathrm{PCO}_{2}>5.9 \mathrm{kPa}\right)$ all six of the normocapnic patients (nos 9-14 in the table) and three of the eight hypercapnic patients (Nos 2, 4, and 5) had definite or probable abnormalities of the pituitary fossa on the $x$-ray film.

The radiological features of sellar osteoporosis are lack of bone density (D) with thinning of the lamina dura (A), while erosion (interruption or disappearance) of the lamina dura ( $B$ and $C$ ) is the characteristic change resulting from raised intracra- nial pressure. $^{\text {rig }}$ Abnormalities consistent with raised pressure were seen in seven of our nine patients in whom changes were noted. In two of these (Nos 9 and 11) abnormalities consistent with osteoporosis were also present, while the remaining two showed osteoporotic changes only. Examples of abnormal $x$-ray films are shown (figs $1-4$ ).

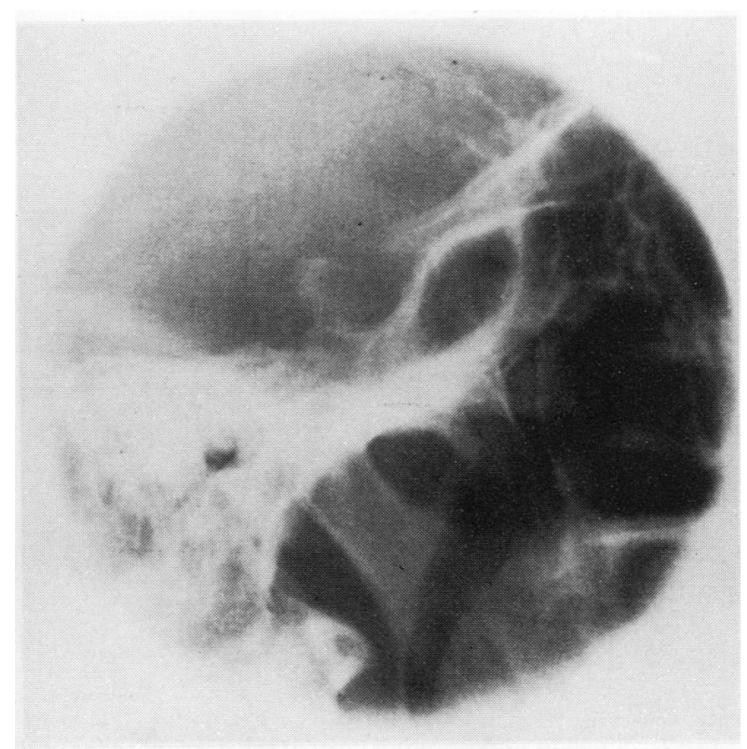

Fig 1 Thinning of the lamina dura of the dorsum sellae. 


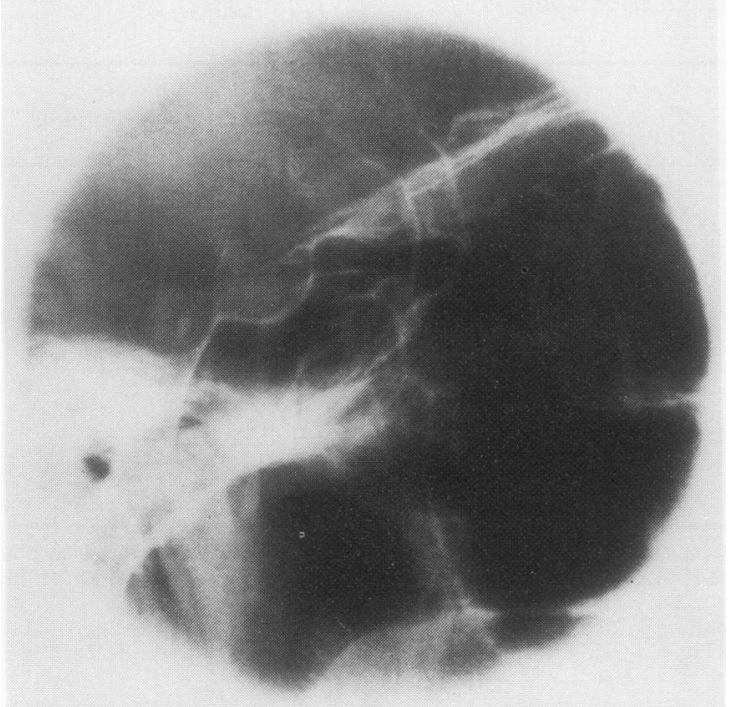

Fig 2 Erosion of the lamina dura of the dorsum sellae.

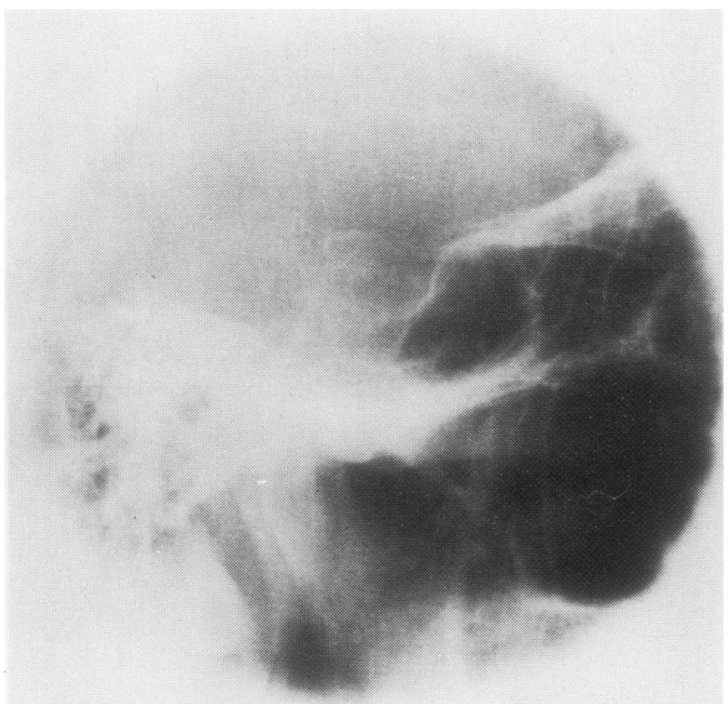

Fig 3 Erosion of the lamina dura of the dorsum sellae and of the floor of the pituitary fossa.

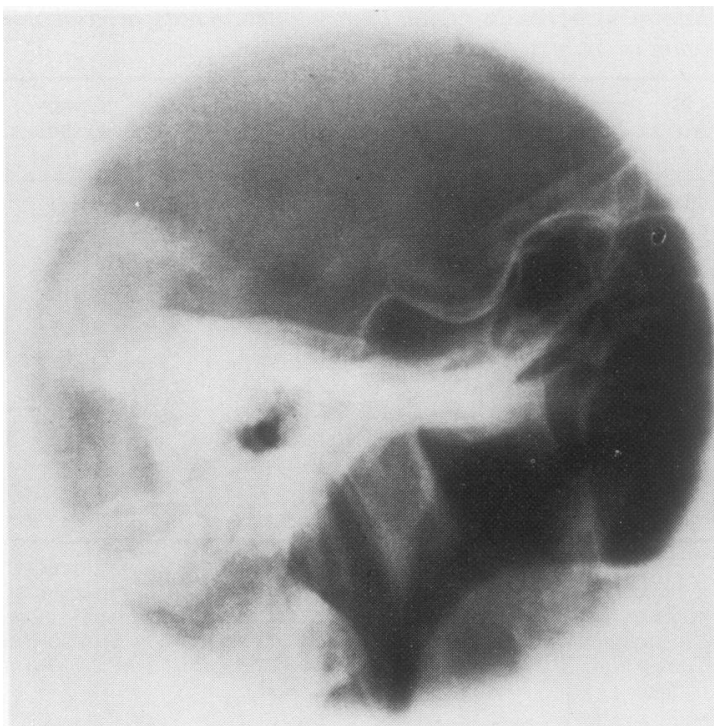

Fig 4 Erosion of the lamina dura and general reduced density of the dorsum sellae.

\section{Discussion}

Our finding of an increased prevalence of changes of the sellar lamina dura on skull radiographs of patients with chronic bronchitis confirms the original observation of Newton and colleagues. ${ }^{1}$ While we agree that most of these radiological changes are in keeping with increased intracranial pressure, we have shown they are not an invariable accompaniment of chronic hypercapnia as was assumed in the original paper. Five of our eight hypercapnic subjects had normal pituitary fossa appearances. In particular patients 1,3 , and 6 had had arterial blood gases monitored for four years, confirming the chronicity of hypercapnia; and the last of these, still without abnormalities of the pituitary fossa, had been admitted with headache and papilloedema caused by raised intracranial pressure on two occasions. In addition, all six of the normocapnic patients had definite changes or probable abnormalities. Interestingly, one control subject had definite and another probable pituitary fossa changes. These controls, however, were a random selection of men from an urban population attending for urgent skull $x$-ray examination and chronic bronchitis was not excluded.

Four of our patients showed distinctive radiological features of osteoporosis with lack of bone density or thinning of the lamina dura either accompanying erosive changes or on their own. These changes are unrelated to steroid treatment. The table in the paper of Newton and colleagues shows that four of 
their 10 subjects also had thinning of the lamina dura, three with and one without additional erosive changes. No mention was made of osteoporosis and indeed no special reference was made to this finding, which was accepted as one of the changes to be expected in patients with raised intracranial pressure.

As chronic hypercapnia can apparently no longer be accepted as the main cause of these pituitary fossa changes, we believe that chronic hypoxia merits consideration as the aetiological factor. Recently we have showed other important deleterious effects of hypoxia in patients with chronic obstructive airways disease who have suppression of the hypothalamic-pituitary-testicular axis resulting in low testosterone production ${ }^{23}$ and organic sexual impotence. ${ }^{10}$ In turn this anabolic steroid suppression may also contribute to the loss of muscle mass found in emphysema. ${ }^{11}$ All 14 of our patients were hypoxic. Osteoporotic changes might be related to chronic hypoxia itself or indirectly to the anabolic steroid suppression, as it is recognised that osteoporosis may be caused by testosterone deficiency..$^{12}$ Another factor might be cigarette smoking, which is known to be associated with an increased prevalence of osteoporosis in postmenopausal women. ${ }^{13}$ Moreover, hypoxia could contribute to raised intracranial pressure by virtue of increasing cerebral blood flow. ${ }^{14}$ If, however, we are correct in assuming that chronic hypercapnia is not responsible for the erosive changes of the sella turcica, we might reasonably question whether such radiographic appearances in this condition are indeed due to a general increase of intracranial pressure. Fry and du Boulay $^{8}$ found pituitary fossa changes identical to those of raised intracranial pressure in $7 \%$ of hypertensive patients and suggested two possible mechanisms: either raised intracranial pressure itself or local pressure from excessive vascular pulsation. Since hypoxia is known to enhance cerebral blood flow $^{14}$ and to engorge intracranial blood vessels, ${ }^{15}$ perhaps these erosive changes of the sella turcica can be produced over years by local pressure from engorged pulsatile internal carotid arteries or engorged venous channels.

In conclusion, we believe that hypercapnia is not a prerequisite for the development of pituitary fossa changes in chronic bronchitis and suspect that hypoxia may be more important. Our findings suggest that osteoporosis may indeed on occasions be responsible for the radiological abnormalities, while sometimes it contributes to the abnormal appearance. Erosive changes, however, probably occur more frequently than porotic ones and may be caused by local vascular or general raised intracranial pressure. The mechanisms for the development of pituitary fossa changes in chronic bronchitis are complex and have yet to be fully elucidated.

We would like to thank Dr WB James and radiography staff at the Southern General Hospital for help in collecting the control radiographs.

\section{References}

' Newton DAG, Bone I, Bonsor G. Chronic hypercapnia and radiological changes in the pituitary fossa. Thorax 1978;33:684-5.

${ }^{2}$ Semple Pd'A, Watson WS, Beastall GH, Bethel MIF, Grant JK, Hume R. Diet absorption and hormone studies in relation to body weight in obstructive airways disease. Thorax 1979;34:783-8.

${ }^{3}$ Semple Pd'A, Beastall GH, Watson WS, Hume R. Serum testosterone depression associated with hypoxia in respiratory failure. Clin Sci 1980;58:105-6.

4 Semple Pd'A, Beastall GH, Watson WS, Hume R. Hypothalamic-pituitary dysfunction in respiratory hypoxia. Thorax 1981;36:605-9.

${ }^{5}$ Medical Research Council Committee on Research into Chronic Bronchitis. Questionnaire on respiratory symptoms. London: Medical Research Council, 1966 (revised 1977).

- Cotes JE. Lung function. 3rd ed. Oxford: Blackwell, 1973.

7 du Boulay GH. Principles of x-ray diagnosis of the skull. 2nd ed. London: Butterworths, 1980.

- Fry IK, du Boulay GH. Some observations on the sella in old age and arterial hypertension. Br J Radiol 1965;38:16-22.

'Sutton D. A textbook of radiology and imaging. 3rd ed. Edinburgh: Churchill Livingstone, 1980.

${ }^{10}$ Semple Pd'A, Beastall GH, Hume R. Sexual dysfunction, low serum testosterone and respiratory hypoxia. Br J Sex Med 1980;62:48 and 53 .

"Hutchinson DCS, Cook PJL, Barter CE, Harris H, Hugh-Jones P. Pulmonary emphysema and alpha-1-antitrypsin deficiency. Br Med J 1971;1:689-94.

12 Bassan J, Frame B, Frost H. Osteoporosis: a review of pathogenesis and treatment. Ann Intern Med 1963;58:539-50.

${ }^{13}$ Daniell HW. Osteoporosis of the slender smoker. Arch Intern Med 1976;136:298-304.

${ }^{14}$ Lennox W, Gibbs EL. Blood flow in brain and leg of man and changes induced by alteration of blood gases. J Clin Invest 1932;2:1155-77.

is Crofton J, Douglas A. Respiratory diseases. 2nd ed. Oxford: Blackwell, 1975. 